\title{
«LA VENTA AMBULANTE Y SUS MERCADOS (EL CASO DE LA PROVINCIA DE ALICANTE)»
}

\author{
José Costa Mas y Gregorio Canales Martínez
}

La venta ambulante ha cumplido tradicionalmente la misión primordial de subsanar las insuficiencias de los canales de distribución y suplir las carencias, a nivel local, de unos equipamientos comerciales embrionarios. En la actualidad, aunque enmendadas muchas de aquellas deficiencias, no cabe enjuiciar dicha práctica mercantil como residual, dada la amplitud de sus manifestaciones y el respaldo de unos hábitos de compra extendidos entre dilatadas capas de población, a menudo urbana. Eso sí, ha mudado de signo, pues, en detrimento de la trajinería tradicional y del deambular itinerante por largos derroteros, se ha potenciado la modalidad de ambulancia que hace escala periódica en determinadas poblaciones, estacionándose regularmente en unos recintos acotados ex profeso: los mercadillos, elementos mercantiles multifuncionales donde, a diferencia de gran parte de los establecimientos del comercio convencional, que presentan una estricta especialización, se oferta gran variedad de productos (orientados a servir en general las necesidades más cotidianas, lejos de toda sofisticación).

Mientras que ciertas modalidades (grandes almacenes, supermercados, etc.) que tienden a imponerse en el comercio sedentario son proletarizantes, los empleos generados por la ambulancia, en número creciente en los últimos años, son desempeñados por autónomos, gentes que se «establecen» por cuenta propia (bien que en ocasiones les acompañe un marchamo de marginación). Aunque su distribución es bastante ubicua por toda la provincia alicantina, auténticos focos de ambulancia se han consolidado en ciertas poblaciones, como un elemento decisivo [88] en la economía de las mismas, al punto de inducir otras actividades comerciales o manufactureras, como es el caso de Cox, con sus almacenes de frutas y verduras, y el de Albatera, con su confección textil ${ }^{1}$.

La importancia que antaño asumió el comercio ambulante, o manifestaciones afines, en el ámbito de la provincia alicantina, se desprende, en una primera aproximación, de diversas publicaciones que contienen referencias a este tema.

Un historiador nos remite a la importante actividad trajinera de los moriscos de los secanos valencianos: una red de préstamos y deudas «marcaba el itinerario de esos vendedores ambulantes» ${ }^{2}$.

El geógrafo Bernabé Maestre ${ }^{3}$ ha trazado una lúcida panorámica de las corrientes comerciales y de las formas tradicionales de ambulancia en el ámbito de la actual provincia de Alicante; destaca que en las ferias y sobre todo en los mercados «l'oferta depenia, d'una part, de mercaders ambulants i marxantons, especuladors, etc. que, seguint un itinerari prefixat anaven pels mercats, i d'altra, dels llauradors que portaven llurs productes».

\footnotetext{
${ }^{1}$ En un próximo artículo se abordará el análisis de estos dos casos, paradigmas de cuanto el arraigo de una ambulancia dinámica puede representar para una población por sus importantes repercusiones geoeconómicas.

Nota bene: En el presente texto mantenemos la toponimia original, con la salvedad de las ciudades que son o fueron cabeza de partido.

${ }^{2}$ HALPERIN DONGHI, Tulio: Un conflicto nacional. Moriscos y cristianos viejos en Valencia, Valencia, Institució Alfons el Magnànim, Diputació Provincial, 1980, 323 pp.; vid. pp. 73-75.

${ }^{3}$ BERNABÉ MAESTRE, Josep M.: Indústria i subdesenvolupament al País Valencià, Mallorca, Ed. Moll, 1975, 109 pp.; vid. pp. 42-52.
} 
Esos mercados, que concentraban la oferta en algunos núcleos, solían ejercer atracción sobre un hinterland más o menos amplio, desprovisto de otras fuentes de aprovisionamiento. Así, p. ej., se evidencia en Denia, sobre la que un informe, de 1927, argüía que «la población es agrícola, el término cuenta con más edificios que el casco» y estas gentes «solo vienen a Denia los domingos para cumplir sus deberes religiosos y hacer sus compras», por lo que en esos días se debía seguir celebrando mercado, de lo contrario los trabajadores del campo «se verían obligados a perder medio día de jornal» o bien «irían a surtirse a otros pueblos» ${ }^{4}$.

Aparte de estas ofertas puntuales y periódicas, había «formes totalment ambulants: traginers i marxantons que anaven per les cases de camp oferint galindaines, quincalla, teixits, etc.»; comercio todo él organizado [89] -como apunta J. M. Bernabé- de acuerdo con los ritmos impuestos por la intermitencia de los mercados y la disponibilidad de numerario vinculada a la estacionalidad de las cosechas, lo que «obligava als venedors a formes de vida itinerants»; eran los carreteros, buhoneros y arrieros que, entre otras zonas de contacto abundaban singularmente en el valle del Vinalopó, fluido corredor entre la Meseta y el litoral alicantino, donde sobre todo la arriería se ejercía a tiempo parcial, a cargo de jornaleros o pequeños propietarios agrícolas.

Dentro de estas formas de comercio existían varios modelos. Uno consistía en conectar el puerto de Alicante con el interior, intercambiando las mercancías descargadas en él (tejidos, pescado salado, coloniales...) con las destinadas al embarque (cereales, frutos secos, azafrán, lana, vino...); los focos de ese comercio se desgranaban desde la propia Alicante por todo el eje del Vinalopó e incluso por la Foia de Castalla (Onil se especializó en el tráfico de drogas), hasta que el ferrocarril Madrid-Alicante, inaugurado en 1858, hizo batir en retirada a la trajinería.

Otro modelo estribó en dar salida a producciones artesanas o manufactureras, tal como los tejidos bastos y mantas que, fabricados en los núcleos textiles de les Valls d'Alcoi, se llevaban a los mercados de Castilla con la contrapartida de cereales, lana y otros productos deficitarios en la provincia. Bien a menudo estas formas de comercio desempeñaron un papel decisivo en el origen o potenciación de una serie de artesanías (después industrializadas por lo general).

En Crevillent eran los propios tejedores de esteras quienes «las esparcen por toda la península y aun por los reynos extraños», según observa Cavanilles a fines del setecientos, quien atestigua haberlos visto en París vendiéndolas con el marbete de tapis de l'Espagne ${ }^{5}$. Práctica similar, bien que en un área más reducida, se daba coetáneamente en Elda con todo tipo de trabajo de esparto. Una vez mediada la pasada centuria, en Elche y Elda se desarrolla la artesanía del calzado; algunos artesanos -señala J. M. Bernabé- comerciaban también su producción y otros trabajaban para los trajineros tradicionales que suministraban la materia prima y, buenos conocedores del mercado, colocaban los acabados en itinerancia.

Un proceso semejante se produjo en Gata de Gorgos y Pedreguer, donde los trajineros trocaban arroz, salazones, etc. por las labores de pleita de palmito del campesino (espuertas y sombreros), y fueron [90] dichos comerciantes quienes hacia 1885 montaron los primeros talleres para el acabado de esos artículos ${ }^{6}$.

Un ejemplo muy conocido de itinerancia es la desarrollada tradicionalmente por las gentes de Xixona con base en dos producciones propias, marcadas por una fuerte estacionalidad:

\footnotetext{
${ }^{4}$ Archivo Municipal de Denia, sig. III - 7, año 1927, Mercado dominical. Antecedentes y faceta.

${ }^{5}$ Cit. por GOZÁLVEZ PÉREZ, Vicente: La industria de esteras y alfombras en Crevillente, Alicante, Círculo de Economía, 1976, 41 pp.; vid. pp. 14-15.

${ }^{6}$ COSTA MAS, José: El Marquesat de Dénia. Estudio geográfico, Universidad de Valencia, 1977, 595 pp.; vid. pp. 466-467.
} 
los helados y los turrones?.

A escala más reducida también la producción cerámica y alfarera de Biar y Orba era distribuida por los trajineros locales.

En algunos casos esa ligazón entre industria y trajinería local ha persistido. Así, en Benilloba (Valls d'Alcoi), especializada de antiguo en la confección doméstica de mantas, los propios artesanos las vendían de forma ambulante; en los años cuarenta había más de cien telares manuales fabricando un tipo de manta ordinaria que apelaron «coreana»; hoy existen allí varias fábricas mecanizadas y pasan del centenar los camiones que en itinerancia distribuyen las mantas de Benilloba y aun parte de las producidas en poblaciones de la vecina provincia de Valencia (Onteniente, Bocairent $)^{8}$.

La itinerancia pura, el deambular por largos derroteros, ha ido en decadencia, pero no así la forma de ambulancia que en periplos centrípetos, «se detiene en ciertos lugares prefijados -los mercadillos-, y sobre aquélla y sobre éstos incide, básicamente, el presente estudio, que se estructura en cuatro apartados. En los dos primeros se expone una caracterización del vendedor y del mercadillo, a nivel general, y en los siguientes se particulariza, para el caso de la provincia alicantina, la cuantía y localización de los ambulantes, las mercancías objeto de transacción y el análisis por encuesta de varios mercadillos representativos.

\section{EL VENDEDOR AMBULANTE: SU PROBLEMÁTICA PROFESIONAL}

En general se considera como venta ambulante el ejercicio de comercio al por menor fuera de un establecimiento comercial permanente, en la vía pública, o en solares y espacios abiertos. Ahora bien, se pueden distinguir dos formas de ambulancia, que a veces coinciden en un mismo comerciante (sincrónica o sucesivamente): la itinerante en puridad, de ubicación espacial variable y no sujeta a periodicidad temporal ni a ningún tipo de horario (a menudo en una misma jornada se recorren varias localidades), y, de otra parte, la concurrencia a mercadillos y ferias [91] comerciales cuya localización y periodicidad adopta un carácter habitual. En esta segunda forma se centra nuestro estudio, tal como se dijo en la introducción, y siendo usual designar a los protagonistas de este comercio singular -el de los mercadillos- como vendedores ambulantes, se mantiene aquí para ellos dicha acepción.

Junto a la ausencia de local propio (la tienda del comercio convencional), otro signo diferenciador de esos ambulantes es el transporte de las mercancías por cuenta propia, que por lo general conlleva una motorización que les permite ser autónomos en sus desplazamientos, de frecuencia incluso diaria, no sólo hasta los mercados, ubicados dentro de un ámbito territorial más o menos concreto, sino también a menudo hasta los centros de abastecimiento de los géneros objeto de transacción.

Sólo una parte, aunque sustancial, de los ambulantes son verdaderos profesionales. Sobre esta actividad pesa la etiqueta de marginación, aunque no sea en absoluto generalizable. Ciertamente en muchos casos aparecen como consecuencia de la falta de actividades retribuidas, con carácter permanente, en otros sectores de producción y, en efecto, se constata que en los últimos años el censo de ambulantes se ha multiplicado en conexión directa con la crisis económica como socorrida alternativa al desempleo. Si se indaga en la causalidad del fenómeno se encuadran en él, entre otros, los carentes de bienes raíces, los que «llegaron tarde» al recurso de la emigración a la CEE, o, entre los pequeños agricultores, aquellos que rechazan la vía hacia

${ }^{7}$ JORDÀ BORRELL, Rosa M.: «La industria del turrón en Jijona», Cuadernos de Geografia, n 13 , Valencia, 1973, pp. 57-74.

${ }^{8}$ GONZÁleZ POMATA, Antonio: Alicante, ver y contar, Diputación Provincial, 1980, 255 pp.; vid. pp. 219-220. 
la proletarización que comporta la figura del obrero-campesino; otras veces encaja de lleno en la llamada economía sumergida u oculta, con prácticas extralegales (venta sin licencia, confección doméstica no regulada de las mercancías, etc.). No es infrecuente que el ambulante se vincule a la agricultura, a la artesanía, etc., desempeñando una doble actividad.

Puesta de manifiesto la ineludible necesidad de establecer un marco legal para este tipo de ventas, el 23 de mayo de 1980 se promulgó un Real Decreto regulándolas para que «puedan cumplir su misión primordial» que es la de «complementar el sistema de distribución comercial, especialmente en aquellas zonas en que el grado de abastecimiento sea insuficiente», y al objeto de «coordinar y ofrecer una uniformidad de base entre las distintas ordenanzas y disposiciones de la administración local en esta materia» (B.O.E., 11-VI-1980).

Según ello, los requisitos que debe cumplir el ambulante son los de darse de alta en la cuota fija o licencia fiscal del impuesto industrial y, de cara a los ayuntamientos, satisfacer los tributos que prevean las ordenanzas municipales y estar en posesión de la autorización correspondiente. Esta última es personal e intransferible, de vigencia no superior [92] al año y con indicación precisa del lugar, fecha y horario en que pueda ejercerse la venta, así como del tipo de mercancía autorizada, y tiene carácter discrecional, pudiendo ser revocada por la alcaldía sin que dé origen a indemnización alguna.

Los ayuntamientos pueden aprobar, ajustándose al referido decreto, sus propios reglamentos o normas reguladoras de la ambulancia, a tenor de las peculiaridades de cada población. Así, por lo que atañe a los mercadillos de Alicante, a la hora de conceder la autorización de la alcaldía -que el interesado debe solicitar mediante instancia- son criterios preferentes la antigüedad en la concurrencia al zoco, la carencia de otros medios de vida y la situación de desempleo (excepto si se percibe subsidio).

El ambulante ha de satisfacer, como queda dicho, la llamada licencia fiscal o patente, la cual debe renovar todos los años, lo que normalmente cumplimenta en enero, con fines también a la renovación de la tarjeta de transporte, en su caso. Quedan exentos de ese pago los agricultores con explotaciones propias que venden directamente sus productos; son los llamados colliters o cosecheros, a quienes les basta con acreditar su condición de propietarios de tierras para obtener la licencia (o con la cartilla agrícola, expedida por la Cámara Agraria correspondiente).

Para iniciarse en el negocio de la ambulancia no se requieren grandes dispendios; basta un vehículo, que puede ser un viejo coche o furgoneta de segunda mano, y un reducido capital circulante, pues se procura agilizar la salida de las mercancías, evitando almacenar stocks, y en muchos casos es posible recurrir al crédito, cuando no a productos de elaboración propia.

La ambulancia comercializa una amplia gama de mercancías, como luego se detalla, especializándose cada vendedor en algún tipo de géneros concreto.

Las fuentes de abastecimiento entre las que puede optar son también muy diversas. Así, por lo que respecta a artículos textiles cabe proveerse de fábrica, directamente o a través de representantes, bien en plena temporada, bien fuera de ella (con lo que el precio se abarata), o buscando existencias de fabricación defectuosa a costes reducidos: incluso hay quien trabaja «en depósito» (paga lo que vende; el resto lo devuelve a fábrica). Otra fuente de provisión muy socorrida son los almacenes, donde los ambulantes obtienen precios de cliente al por mayor, a menudo con tres o cuatro meses de plazo; incluso pueden conseguir géneros de temporadas pasadas a peso y muy baratos, de los que también se sirven ocasionalmente en ciertas tiendas (a veces son los propios tenderos los que concurren al mercadillo para dar salida a tales existencias). También es importante el mercar bienes de manufacturación propia, sobre [93] todo en el ramo de la confección textil (mantelerías, colchas, géneros de punto, vestidos sencillos, delantales, etc.), elaborados a nivel familiar, cuando no bajo la práctica de cierto putting-out a domicilio; también es usual en algún tipo de marroquinería (cinturones) y de bisutería y objetos 
de adorno.

En cuanto a los vendedores de frutas y hortalizas, éstos pueden ser, según su fuente de provisión, cosecheros, revendedores o de tipo mixto. Los primeros, a quienes ya se aludió, son generalmente pequeños agricultores que trabajan su explotación en régimen familiar y concurren con su cosecha a los mercadillos, en venta directa de productor a consumidor'; esta figura, que proliferó en diversos municipios agrícolas con regadío tradicional(Cox, Mutxamel, etc.) está en trance de desaparición. Los revendedores actúan como clásicos intermediarios, pudiendo abastecerse de diversas fuentes, ya sea de almacenes mayoristas que existen en diversas localidades (a veces sin desplazarse hasta ellos: los de Cox les proveen directamente en camiones ambulantes), ya de sociedades cooperativas -incluyendo grupos de colonización, asociaciones de productores agrarios, etc.- orientadas a comercializar las cosechas de sus afiliados; también de las lonjas o del mercado central de abastecimiento de frutas y verduras -Mercalicante, en las afueras de la capital, junto a la carretera de Madrid- o de los mercados en origen de productos agrarios (Mercosegura, en Orihuela) o incluso adquiriendo la mercancía directamente del agricultor, lo que es menos frecuente. Por último, hay profusión de ambulantes que se adscriben a una situación intermedia, pues su mercancía sólo en parte es de cosecha propia; muchos eran simples cosecheros-vendedores que se han visto impelidos a adquirir mercancía de otra procedencia, bien porque sus ayudas familiares -los hijos jóvenes- abandonan la agricultura, o bien para ampliar su oferta, tanto en volumen como en variedad de productos.

El ejercicio de ciertas actividades ambulantes choca con los intereses, a menudo contradictorios, de una parte del comercio convencional, que no deja de lamentarse por una competencia calificada de desleal, no tanto la de los mercadillos como la de otros tipos de ambulancia (la itinerante, las ventas a domicilio, etc.) a los que se tacha de anacrónicos y trasnochados, pero que «venden más que los comerciantes establecidos» en opinión de éstos, quienes confían en que la aplicación estricta del mencionado R. D. de 23 de mayo de 1980 permita acabar con los canales [94] de distribución ilegales o irregulares ${ }^{10}$.

A su vez, la mayoría de los ambulantes encuestados acusan el notable incremento -paralelo al del paro y falta de alternativas de los últimos años- del número de competidores del ramo, cuya incidencia no llega a ser compensada -dicen- por la mayor clientela potencial de los mercadillos que, por sus ofertas (calidad ordinaria, precio asequible), crecen en popularidad ante la mengua del poder adquisitivo en esta época de crisis; las quejas se centran sobre todo contra el intrusismo de los vendedores ilegales, sin licencia, y cierta permisividad de las autoridades para con ellos (motivada a menudo por estrictas consideraciones humanitarias).

Esta proliferación del intrusismo viene correlacionada con el encarecimiento de la licencia fiscal, la cual venía suponiendo una anualidad modesta, del orden de 300 a 700 pesetas, pero que desde 1981 ha sufrido un aumento inusitado (p. ej., la patente para la venta de verduras cuesta 14.000 ptas. y para ropa, 21.600 ptas.).

Aparte, los ambulantes que concurren a los mercadillos han de satisfacer al ayuntamiento un canon o tasa por ocupación de vía pública, proporcionado a los metros de frontis del puesto que levantan, carga que también ha sido incrementada últimamente en algunos municipios (en Benidorm, p.ej., se pagan 500 ptas. por metro cada día de mercado).

Ante toda esta problemática con que se enfrenta la ambulancia hay constituida una Asociación Profesional Sindical de Vendedores Ambulantes de la Provincia de Alicante, con sede en la capital, para la «defensa, representación y mejora de la profesión en sus diversos

\footnotetext{
${ }^{9}$ Incluso se da el caso curioso de la explotación agrícola de cierta entidad -concretamente en Xixona- cuyo empresario detenta un puesto de venta en un zoco de la capital, a cargo de asalariados.

${ }^{10}$ COCIN de Alicante e IRESCO: Estudio sobre la problemática del comercio detallista en la provincia de Alicante, Alicante, 1979, 59 pp.; vid. pp. 17 y 44-45.
} 
aspectos» -según rezan sus estatutos-, la cual cuenta con un censo de cerca de 2.000 afiliados, incluyendo a vendedores que, procedentes de otras provincias, desempeñan su comercio en ésta.

De la consulta del archivo de la Asociación ${ }^{11}$ se desprende que las poblaciones que aportan mayor número de miembros (con la salvedad de que en algunos casos no consta la residencia) son Alicante con 389, Elche con 182 y Albatera con 136; las tres suman el 35\% del total. Superan la veintena de asociados Orihuela (65), Benidorm (49), Murcia y pedanías (43), Crevillent (38), Alcoy (33), Callosa de Segura (24), Denia, Sant Vicent del Raspeig y Villajoyosa; con 20 figuran Altea y Gata. En general estas cifras guardan proporción con el monto de patentes de [95] ambulancia que existen en dichas poblaciones, teniendo presente que a nivel provincial la afiliación es del orden del $50 \%$ de los vendedores con licencia. La excepción más notable es Cox, con sólo 19 afiliados pese a ser un destacado foco de ambulantes; la razón es que no se sindican como tales, ya que pasan por ser a la vez agricultores y entre los requisitos exigidos para asociarse figura el de «ejercer la venta ambulante como única profesión». Por comarcas, las de mayor afiliación son el Camp d'Alacant, con 431; el Bajo Segura, con 284 y el Baix Vinalopó, con 237; de otras provincias destacan los 71 de Murcia (sobre todo de la Vega Media) y los 61 de Valencia (la Safor y l'Horta).

Uno de los fines más importantes de la Asociación consiste en «negociar, concertar y suscribir acuerdos y convenios con toda clase de organismos que afecten o interesen a la profesión»; en esta línea se han suscrito conciertos con algunos ayuntamientos (Orihuela, Torrevieja, Xixona...) sobre la tasa a devengar por puesto, logrando que sea más ajustada y que su cobro en esos mercadillos corra a cargo de un miembro de la Asociación.

\section{LOS MERCADILLOS}

Son unos elementos comerciales de carácter singular que se caracterizan por ser lugares públicos, de ubicación espacial concreta, destinados a la venta al por menor y al aire libre en unos puestos o tenderetes que los ambulantes montan a diario o bien, caso más frecuente, con sujeción a una periodicidad semanal.

El Real Decreto de 23 de mayo de 1980 ratifica o sanciona la práctica comercial en los mercadillos y ferias entonces existentes y habilita a los ayuntamientos para autorizar otros nuevos, previo informe de la Cámara Oficial de Comercio de su demarcación sobre la necesidad de los mismos, fijando el número de puestos máximo y el tipo de productos que puedan expedir -de los que se excluye el pescado, la carne y los embutidos- sin que los días de celebración puedan sobrepasar un máximo de dos por semana, de los que al menos uno deberá ser festivo. Según el referido decreto, en los municipios donde exista algún mercadillo, la venta ambulante sólo puede practicarse en el marco del mismo durante los días en que se celebre, y la autorización municipal debe contener referencia expresa al emplazamiento reservado para el titular de un puesto.

Los mercadillos pueden presentar tres alternativas por lo que a las mercancías se refiere. Los hay que sólo ofertan productos alimenticios, generalmente perecederos (frutas y verduras), mientras que otros expiden exclusivamente mercancías de uso, de carácter textil, artesanalo [96] de ornato y similares. Pero el caso más difundido es el mercadillo mixto, en el que coexisten ofertas de ambos tipos.

Amplios estratos de consumidores se rigen en la actualidad por unos hábitos de compra tendentes a satisfacer sus necesidades más cotidianas en complejos comerciales con amplia superficie de venta y oferta muy diversificada. De ahí que una dotación deficitaria en grandes almacenes populares, de comercio mixto, a menudo justifique plenamente la presencia de

\footnotetext{
${ }^{11}$ Por deferencia del Sr. Lillo, su actual presidente.
} 
mercadillos importantes, por su dimensión y atractivo, que ofertan tanto productos de tipo «diario» (alimentación, droguería) como mercancías ocasionales no especializadas (confección textil, calzado, menaje, etc.).

Es más, la venta de frutas y verduras en mercadillo se corresponde frecuentemente con una clara insuficiencia de los mercados de abasto en relación a la densidad demográfica y/o a una polarización de los mismos en el área central de las ciudades en detrimento de la periferia, lo cual provoca una demanda insatisfecha (en productos y en precios). Por añadidura, la celebración semanal o bisemanal de los mercadillos se adecua correctamente al hábito de la compra alimentaria de igual periodicidad que se ha generalizado al compás de la dotación hogareña en frigoríficos.

Con independencia del originario cariz rural de estos elementos comerciales, hoy la práctica totalidad de los municipios de la provincia con cierta entidad de población (en general, por encima de 1.500 habitantes) cuentan con algún mercadillo. En los núcleos pequeños se celebra una sola vez por semana y el número de puestos es reducido, predominando las mercancías de consumo cotidiano; en el otro extremo está la ciudad de Alicante, con tres mercadillos, uno de los cuales cuenta con un millar de puestos durante dos días cada semana. Cabe observar que todos los municipios litorales con una proyección turística prioritaria y fuertes contingentes de población flotante con alto nivel de consumo, poseen mercadillos de importancia, sobre todo en época estival.

La inserción de estos elementos dentro de las tramas urbanas también es varia, desde una localización central en el casco antiguo, que es muy frecuente (p. ej. en Orihuela, Torrevieja, Villena, Almoradí), hasta un emplazamiento en las afueras de la población (Benidorm, Villajoyosa). Las zonas de ubicación preferente, en busca de la máxima accesibilidad, son las inmediaciones de los centros comerciales y de los mercados municipales de abastos; cuando estos últimos existen suelen disponer de unas áreas anexas especialmente acondicionadas para el asentamiento de mercadillos; hay una clara asociación espacial entre ambos elementos (casos de Alicante y Elche..., entre otros muchos). Otra situación deseable es toda zona urbana con alto nivel de densidad peatonal [97], localizada estratégicamente, a menudo coincidente con los espacios más representativos del casco, que son auténticos focos de animación (plaza del ayuntamiento, aledaños de la iglesia, calles de paseo...).

Recientes disposiciones legales interfieren en su ubicación concreta; así, respecto a los mercadillos existentes con anterioridad al decreto de mayo de 1980, éste los ratifica en los lugares habituales de celebración «salvo los que se encuentren en calles peatonales comerciales, en cuyo caso deberá procederse a su traslado», y prohíbe, consiguientemente, la implantación de un nuevo zoco en este tipo de zonas, disponiendo, además, que en las ciudades de más de 50.000 habitantes o capitales de provincia sólo se podrá instalar el mismo fuera del perímetro urbano exceptuado», el cual se determinará por el ayuntamiento, oída la Cámara de Comercio correspondiente, teniendo en cuenta «el nivel de equipamiento comercial existente en la zona» y «la adecuación de éste a la estructura de consumo de la población, así como la densidad de la misma»; perímetro que «deberá ser homogéneo y continuo y comprender en cualquier caso la zona central del casco urbano».

Sobre esta cuestión, que puede conllevar en cierto plazo un trasvase notable de los zocos tradicionales en el seno de la estructura urbana, existe ya un análisis y unas propuestas elaboradas para la provincia de Alicante por el Instituto de Reforma de las Estructuras Comerciales $^{12}$.

De hecho muchos mercadillos, que absorben superficies más o menos amplias de suelo

12 IRESCO: Programa de tratamiento integral del comercio. Estudio urbanístico-comercial de la provincia de Alicante, diciembre 1980, 4 vols. 
vacante, coinciden con calles o tramos de alto nivel de tráfico viario y peatonal, causando problemas de estrangulamiento y agravando la congestión circulatoria, aparte de otras molestias ocasionadas a los vecinos de esas áreas residenciales (ruidos y vocerío de madrugada, reducción de la zona de aparcamiento, etc.). De ahí que algunos ayuntamientos acaben por disponer el traslado de los zocos a puntos menos conflictivos, como ocurrió con el de Campoamor, en Alicante, ya en 1968, o con el de Benidorm, transferido a fines de 1981 a la zona de la avenida de Nicaragua, al lado opuesto donde se ubica el núcleo de población fija de esta villa turística (en un recinto de una hectárea se levantan más de 400 puestos de géneros textiles, calzado y artesanía diversa).

Otras veces su movilidad responde a la decisión municipal de descentralizar ese servicio a favor de la periferia urbana; es el caso la de rotación del zoco de frutas y verduras de Elche que, según días, va emplazándose alternativamente en los distintos barrios. El ayuntamiento de Alicante también ha sopesado la conveniencia de descongestionar el [98] mercadillo de Campoamor y llevar los puestos de alimentación a los barrios de Virgen del Remedio, Ciudad de Asís y Los Ángeles, algunos de los cuales lo han solicitado expresamente a través de las asociaciones de vecinos.

En los mercadillos hay vendedores que tienen reservado el sitio donde levantar el tenderete, siempre en los puntos más concurridos por el público; son los ambulantes «de toda la vida», los más profesionalizados. Los demás ocupan los lugares vacantes a medida que van llegando cada día de mercado y su asistencia no es tan regular como la de los llamados «fijos», quienes en la encuesta muestran, en general, una mayor satisfacción por la marcha del negocio, sobre todo los que llevan más años en él y detentan los mejores puestos en las plazas más calificadas.

La gran mayoría de los ambulantes, haciendo gala de su condición, tienen una extrema movilidad, concurriendo a lo largo de la semana a diversos mercadillos y no siempre en un ámbito estrictamente comarcal. A menudo efectúan un itinerario constante, a tenor de las fechas de celebración de mercado en las diversas localidades; así, para un vendedor del Bajo Segura un itinerario ideal, a tenor de la rentabilidad potencial de las plazas, puede ser el siguiente: los lunes en Elche; martes, Orihuela; miércoles, Benidorm, Cartagena o Guardamar; jueves, Alicante; viernes, Torrevieja, y sábados, Alicante, Elche o Almoradí. Los puntos extremos para el ambulante de dicha procedencia vienen a ser Cartagena, Albacete y Benidorm.

Hay que señalar, por último, que los mercadillos suponen una buena fuente de ingresos, para los ayuntamientos; el de Alicante, p.ej., recauda por este concepto alrededor de 27 millones de pesetas al año. Además cuenta con los ingresos obtenidos por la licencia fiscal de ambulancia que, como recursos locales, revierten en su inmensa mayoría a los ayuntamientos.

\section{CENSO DE AMBULANTES DE LA PROVINCIA Y SU DISTRIBUCIÓN GEOGRÁFICA}

Tal como se ha indicado, el vendedor ambulante viene obligado a renovar anualmente su licencia, requisito que cumplimenta por lo general a comienzos de cada año. Por ello, para obtener una aproximación al censo de estos activos, del cúmulo de licencias físcales del impuesto industrial registradas en $1980^{13}$ se han vaciado las patentes correspondientes al comercio ambulante durante los meses de enero y febrero [99], las cuales se puede estimar que suponen del orden del $85 \%$ de todas las licencias de este tipo expedidas en el referido año, pues si bien las renovaciones a partir de marzo son muy escasas hay que tomar en consideración las altas

\footnotetext{
13 Último año que se nos permitió consultar en la Delegación Provincial de Hacienda, a cuyo personal agradecemos la deferencia.
} 
correspondientes a quienes se iniciaron en esa actividad después de febrero.

El monto total de patentes de ambulancia resultante de dicho vaciado asciende a 3.577, a lo que habría que sumar el $15 \%$ de esa cantidad por la razón expuesta y, asimismo, considerar el número, de difícil estimación pero sin duda sustancioso, de los agricultores que venden en ambulancia sus cosechas y que, en aquella fecha, estaban eximidos del requisito de la patente ${ }^{14}$; además muchos ambulantes se valen de ayudas familiares para el desempeño de este comercio. De todo ello resulta que los efectivos dedicados a tal actividad y las familias de ellos dependientes en la provincia alcanza cierta consideración, y más teniendo presente que en los dos últimos años se asiste a un notable incremento de ambulantes a tenor de la contracción de oportunidades y del mayor desempleo.

En el mapa núm. 1 se representa la distribución comarcal de esas 3.577 licencias, según el lugar de residencia de sus titulares, en consonancia con los datos del siguiente cuadro:

TABLA I

Reparto comarcal de las patentes de ambulancia

$\begin{array}{lcc}\text { Comarcas } & \underline{\text { Licencias }} & \underline{\%} \\ \text { Camp d'Alacant (CA) } & 818 & 22,87 \\ \text { Bajo Segura (BS) } & 723 & 20,21 \\ \text { Baix Vinalopó (BV) } & 680 & 19,01 \\ \text { Vinalopó Mitjà (VM) } & 420 & 11,74 \\ \text { La Marina (LM) } & 285 & 7,97 \\ \text { Marquesat de Dénia (MD) } & 200 & 5,59 \\ \text { Les Valls d'Alcoi (VA) } & 194 & 5,42 \\ \text { Alto Vinalopó (AV) } & 171 & 4,78 \\ \text { Foia de Castalla (FC) } & 86 & 2,41 \\ & & 100\end{array}$

Por comarcas, las de mayor peso son las del Camp d'Alacant, Bajo Segura y Baix Vinalopó, que suman casi dos tercios de las patentes de [100] ambulancia provinciales; también destacado figura el Vinalopó Mitjà con más del 11\% de las mismas, mientras que cuatro comarcas quedan sensiblemente por debajo del $8 \%$, porcentaje que ostenta La Marina.

La distribución por municipios de este fenómeno queda visualizada en el mapa núm. 2, a tenor de los datos que constan a continuación:

\section{TABLA II}

\footnotetext{
${ }^{14}$ Por entonces el número de ambulantes fuera de la legalidad posiblemente sería escaso, dado que la cuota a devengar por la licencia fiscal era exigua, circunstancia que ya no se da a partir de 1981.
} 


$\begin{array}{lccccc}\text { Municipios } & \underline{\text { Licen }} & \underline{\%} & \underline{\text { Municipios }} & \underline{\text { Licen } .} & \underline{\%} \\ \text { Alicante } & 659 & 18,42 & \text { Benidorm } & 86 & 2,40 \\ \text { Elche } & 548 & 15,32 & \text { Aspe } & 70 & 1,96 \\ \text { Albatera } & 208 & 5,81 & \text { Petrer } & 66 & 1,86 \\ \text { Orihuela } & 171 & 4,78 & \text { S. Vicent Rasp. } & 56 & 1,56 \\ \text { Elda } & 134 & 3,75 & \text { Novelda } & 49 & 1,37 \\ \text { Villena } & 124 & 3,47 & \text { Villajoyosa } & 48 & 1,34 \\ \text { Callosa de Seg. } & 105 & 2,93 & \text { Denia } & 46 & 1,29 \\ \text { Alcoy } & 98 & 2,74 & \text { Gata de Gorgos } & 40 & 1,12 \\ \text { Crevillent } & 96 & 2,68 & \text { Otros } & 886 & 24,77 \\ \text { Cox } & 87 & 2,43 & \text { TOTAL } & 3.577 & 100\end{array}$

Alicante y Elche, que son los municipios que cuentan con más ambulantes, concentran un tercio de los existentes en la provincia y en torno al $80 \%$ de los censados en sus respectivas comarcas. En el Bajo Segura, por contra, el fenómeno es menos puntual, bien que descuellan Albatera, Orihuela (que ocupan la tercera y cuarta posición por municipios), Callosa de Segura y Cox; entre los cuatro agrupan el 80\% del censo comarcal de ambulantes. (Nótese que el de Cox está infravalorado por no incluir a muchos cosecheros-vendedores).

Sobresalen también tres poblaciones capitales de comarca y de fuerte peso demográfico, que son Elda, Villena y Alcoy. Otros núcleos destacados corresponden al corredor del Vinalopó (Crevillent, Aspe, Petrel y Novelda) y al litoral turístico (Benidorm, Villajoyosa y Denia).

En resumen, los comerciantes ambulantes, aunque un tanto ubicuos por toda la provincia, se concentran especialmente en su mitad meridional, y dentro de esta zona, destaca con nitidez el área metropolitana Alicante-Elche, que incluye a San Vicent del Raspeig, así como dos grandes ejes que convergen hacia ella, de los cuales el principal es el que arrancando de Orihuela continúa por Cox, Granja de Rocamora, Albatera y Crevillent hasta enlazar con Elche, extremo al que también afluye el eje accesorio que parte de Villena y prosigue por la conurbación Elda-Petrer hacia Novelda y Aspe. [101]

Cabe observar que, aun cuando los ambulantes se localizan mayormente en las ciudades, focos de terciarización por excelencia, a muchos no les es condición indispensable instalarse en ellas pues no precisan recurrir a los servicios de las mismas. Así, p.ej., los hay en las pedanías de la huerta y campo de Orihuela (igual que en la Huerta de Murcia) y en exiguos pueblecitos de las áreas de montaña.

Interesa también subrayar que el papel que desempeñan esos activos desde la perspectiva funcional de las poblaciones donde su presencia es notoria, no es necesariamente proporcional a su número y puede responder a contenidos muy distintos; en efecto, en líneas generales buena parte de los ambulantes radicados en Alicante, por citar el ejemplo más palmario, se puede adscribir a las llamadas actividades no básicas o residenciales de la ciudad dado que prácticamente sólo presta servicio al consumo ciudadano en los mercadillos locales, mientras que en los núcleos donde una ambulancia autóctona de carácter muy dinámico encuentra su razón 
de ser en su proyección de servicio a unas clientelas exteriores, ella se configura como una neta actividad básica o exportadora de tales poblaciones, así en los casos inequívocos de Cox y Albatera.

\section{LAS MERCANCÍAS COMERCIALIZADAS}

Las clases de productos objeto de transacción cubren una amplia gama; y no siempre son bienes, también cuentan los feriantes que ofrecen servicios para la diversión o pasatiempo.

Las patentes de ambulancia especifican la índole de la mercancía que autorizan a negociar según la expresa solicitud del beneficiario. A tenor de esta fuente, se ha elaborado el siguiente cuadro en el que se recogen todas las licencias expedidas en la provincia de Alicante en enero y febrero de 1980:

TABLA III

Clasificación de los ambulantes según tipos de mercancía

Mercancías

Frutas y verduras

Panadería y bollería

Frutos secos

Aves y huevos

Pescado

Bebidas, refrescos

Comestibles varios

Confección

Tejidos

Textil hogar

Mercería

Alfombras

Calzado

Artículos piel, cuero y similares

Juguetes y baratijas

Relojes y joyería

Bisutería

Perfumería

Loza, cerámica, cristal

\section{Licencias}

825

109

72

67

67

52

225

407

200

133

67

29

496

91

162

38

56

32

76 $\underline{0}$

23,06

3,06

2,01

1,87

1,87

1,45

6,29

11,38

5,59

3,72

1,87

0,81

13,87

2,54

4,53

1,06

1,56

0,89

2,13 


$\begin{array}{lcc}\text { Plantas y flores } & 55 & 1,54 \\ \text { Artículos de limpieza } & 56 & 1,57 \\ \text { Artesanía de mimbre y madera } & 33 & 0,92 \\ \text { Ferretería } & 18 & 0,50 \\ \text { Libros y discos } & 29 & 0,81 \\ \text { Feriantes } & 109 & 3,06 \\ \text { Varios* } & 73 & 2,04\end{array}$

$\begin{array}{lll}\text { TOTAL } & 3.577 & 100\end{array}$

*Jergas, 14; artículos de regalo, 11; plásticos, 10; autos, 8; hojalatería y chatarrería, 6; ganado, 6; máquinas de escribir, 3; sombreros, 2; gafas de sol, 2; filatelia, 1; palmas, 1; otros, 9.

El mayor contingente, con mucho, lo compone el ramo de la alimentación, al que atañen el 39'6\% de las patentes. De ellas, más de la mitad corresponden a la venta de frutas y verduras; destaca también el sector de panadería y, entre los «comestibles varios» resaltan los salazones, cuyo consumo es muy tradicional en la provincia. Todavía figuran licencias para pescado y marisco, productos cárnicos y fiambres o embutidos, con anterioridad al decreto de 23 de mayo de 1980 que señala que los productos autorizados en ambulancia estricta «no podrán referirse más que a artículos textiles, de artesanado y de ornato de pequeño volumen» y que excluye de los mercadillos «el pescado, la carne, frescos o congelados, y los embutidos». (Y en efecto, ya no se ofertaban en los mercadillos que visitamos en 1981-82.)

El siguiente capítulo lo conforma el ramo de los textiles que agrupa más del $23 \%$ de las licencias, de las cuales cerca de la mitad corresponde [103] al sector de la confección, secundado por los tejidos -cuya oferta fue antaño predominante- y por el textil-hogar.

De los ambulantes censados, el 16'4\% se dedica a los artículos de piel, cuero y sus sucedáneos. Cuatro quintos de esas licencias se refieren al calzado, una de las mercancías de mayor arraigo -junto a las dos antes citadas- en la ambulancia tradicional; también están representadas la marroquinería, la guarnicionería e incluso la confección en piel y similares.

En comparación con estos tres grandes conjuntos -alimentación, textiles y piel - las demás mercancías quedan muy rezagadas en cuanto al número de licencias (bien que alguna suponga transacciones de alto valor). Las hay, tal como quedó patente en la introducción, vinculadas a manifestaciones características de la industria y artesanía provinciales; otras constituyen sectores clásicos en la venta itinerante, como es la relojería y bisutería, la alfarería y los artículos relacionados con el hogar (limpieza, loza, floristería); y a ello se añade la multisecular actividad feriante.

Es posible discernir concordancias más o menos nítidas entre ciertas mercancías objeto de venta ambulante, de una parte, y determinadas poblaciones, de otra, lo que remite a una cierta especialización en algunos de los núcleos emisores de mercaderes itinerantes.

Así, por lo que a frutas y verduras se refiere, existen dos de tales focos, ambos en plena vega del Bajo Segura, el de Cox, genuinamente especializado, y en su vecindad, el de Granja de Rocamora, con dedicación más incipiente bien que, como es de esperar, la oferta de esta índole es bastante ubicua, destacando también la de los ambulantes afincados en Alicante, Mutxamel, 
Orihuela y diversos núcleos de su comarca, Elche y Aspe, entre otros. Otra vinculación, antaño más patente, es la que existe entre los ambulantes de Xixona y la venta de turrones y helados.

En el ramo de los textiles sobresale reciamente Albatera, foco de ambulantes orientado hacia la confección y retales. En la venta de alfombras y la de mantas ordinarias continúan singularizándose -aunque no en exclusiva- los ambulantes de Crevillent y de Benilloba, poblaciones que cuentan con estos tipos de manufacturas.

Similar fenómeno se repite en otras poblaciones donde se expide parte de la producción local en venta ambulante. En la del calzado sobresale Elche y, en menos medida, Elda y Petrer, si bien al igual que ocurre con los textiles la extracción de los vendedores de calzado es bastante ubicua, destacando Albatera y Benidorm entre los focos secundarios. Otros ejemplos los ofrecen los comerciantes de juguetes vinculados a la [104] Foia de Castalla, los de alfarería surgidos de Agost, y los de artículos de mimbre y junco radicados en Gata de Gorgos.

Por último, más de un centenar de licencias atañen a los feriantes, grupo heterogéneo que abarca tómbolas, pistas de coches infantiles, casetas de tiro, norias, bares ambulantes, funciones de cuadros vivos, etc. y que radica en su mayoría en la ciudad de Alicante, cuya feria de Navidad, por cierto, atrae a muchos de estos bohemios: en 1981 el ayuntamiento recaudó en la subasta de los puestos 13 millones de ptas. (el clima de Alicante «tiene un precio» para tales negocios al aire libre).

En cuanto a la calidad de los productos comercializados la opinión general, referida a los mercadillos, es que mientras las frutas y verduras suelen ser de buena índole, en mercancía de uso se ofertan y demandan preferentemente calidades ordinarias o medianas a precios económicos.

\section{ANÁLISIS DE MERCADILLOS CONCRETOS}

Para completar este estudio se han visitado una serie de mercadillos, escogidos entre los más representativos. No podía faltar entre ellos el de Campoamor que, situado en la ciudad de Alicante, es por su número de puestos y volumen de ventas el más importante, sin duda, de toda la provincia; en él aplicamos, en julio de 1982, una encuesta que cubrió a un quinto de los vendedores, la cual se hizo extensiva a un mercadillo de productos agrícolas cercano, el de la calle de Velázquez ${ }^{15}$.

Los demás mercadillos se decidió elegirlos entre los que presentara una comarca, pues de este modo, partiendo de un marco geográfico y socioeconómico relativamente homogéneo, podrían compararse mejor los distintos tipos de estos singulares centros comerciales, diferenciados sobre todo por su ubicación en varias categorías de entidades de población. La comarca escogida fue la del Bajo Segura en razón de que su ratio de ambulantes relativa a la población comarcal absoluta es la más alta de la provincia y, además, cuenta con los que se pueden considerar los dos focos de ambulancia más significativos (Cox y Albatera). Los mercadillos seleccionados en ella, cuyos vendedores fueron encuestados en julio y agosto de 1981, son el de Torrevieja, por su condición de localidad turística, y los de Orihuela, Almoradí y Rojales, en representación de poblaciones de tamaño grande, mediano y pequeño, respectivamente. [105]

El mercadillo de Campoamor.- Es, con mucho, el de mayor importancia de Alicante, con alrededor de un millar de puestos de venta.

En sus orígenes este tipo de comercio aparece vinculado al mercado de abastos, en búsqueda de la máxima accesibilidad y a modo de complemento del mismo. A comienzos de

\footnotetext{
${ }^{15}$ Agradecemos la ayuda dispensada por los Sres. Andreu Cremades, ex-regidor de mercados del ayuntamiento alicantino, y Josep Lluís Bernabeu, quien dirigió un trabajo sobre este zoco en la Escuela de Profesorado de EGB.
} 
siglo el mercado de Alicante se hallaba entre la Explanada y la plaza del Ayuntamiento, y la lonja situada a espaldas de éste, en la calle Lonja de Caballeros. Con posterioridad el mercado se trasladó a la Rambla de Méndez Núñez y plaza de San Cristóbal, y la lonja a Les Oliveretes (hoy barrio de Sta. Isabel). Por entonces era un mercado al aire libre, en carritos con o sin toldos, y a cuyos puestos fijos, levantados a diario, se añadía todos los sábados una plétora de vendedores-cosecheros.

Después de la erección, en 1921, del edificio del actual mercado central de abastos junto a la avenida de Alfonso X el Sabio (a la que seguiría la construcción de la lonja de San Fernando, entre las calles García Morato y Capitán Segarra), los vendedores sin puesto fijo se establecieron a la intemperie en las vías públicas de los alrededores, concretamente en las calles de Quintana y de Velázquez para la venta de productos agrícolas, y para la de mercancías de uso en Calderón de la Barca, vía ya entonces de mucho tránsito por su situación entre el mercado, de un lado, y de otro la plaza de toros, por las paradas de tranvías (después, de autobús) de los pueblos colindantes e incluso por la feria navideña de Campoamor. Pronto los tenderetes invadieron también la calle Capitán Segarra y la fachada del mercado frente a Alfonso el Sabio. A los vendedores que allí acudían los sábados y los jueves, se sumaron los que levantaban a diario su puesto por falta de capacidad del mercado central.

Así hasta que en marzo de 1968, a instancias del ayuntamiento y debido a la congestión de dicho espacio, a problemas de circulación, a quejas del comercio sedentario y de la vecindad, y también por razones de imagen, el zoco de ambulantes fue trasladado al paseo de Campoamor (excepción hecha de la venta callejera de frutas y verduras que aún subsiste en Velázquez), liberando de aquella servidumbre a tres calles muy céntricas y mutando de emplazamiento la actividad feriante que venia explayándose todas las Navidades en Campoamor.

Dicho paseo ha resultado ser un lugar idóneo para el desenvolvimiento del zoco, pues presenta una amplia explanada, cerrada al tráfico rodado, más que capaz para los puestos inicialmente previstos -algo más de 400 que eran los ya existentes en las inmediaciones del mercado de abastos- y por añadidura, en una situación casi tan céntrica como la de este último, del que dista un corto trayecto. Limítrofe con la plaza de España, la cual es nudo clave de los transportes públicos que enlazan el [106] corazón de Alicante con los barrios y con las poblaciones vecinas de Sant Vicent del Raspeig y El Palamós, y jalonado por dos grandes ejes de circulación -las avenidas de Alcoy y de Jijona- ejerce atracción sobre una densa y dilatada zona urbana (centro, Carolinas Bajas, San Antón, El Altozano, Los Ángeles, Santa Isabel...)

En principio se habilitó exclusivamente el paseo estricto, dividiendo el espacio en tres zonas: en el primer tramo, junto a la plaza de España, se situaron los puestos diarios de mercancías de uso; en la zona intermedia, más ancha, los de frutas y verduras, y en la última los puestos a levantar sólo los jueves y sábados.

Superadas las iniciales reservas de parte de los ambulantes de la calle Calderón, que se resistían al traslado, ya en el tercer día de mercadillo -sábado, 9 de marzo de 1968-Campoamor registró la afluencia de 250 vendedores de fruta y verduras, con una oferta que rondaba las 50 toneladas, aparte de 26 puestos de plátanos, más 130 de confección y artículos varios (de ellos, unos 70 de calzado), 40 de huevos y granjería y 20 de flores, plantas decorativas y animales de compañía; en total, 466 puntos de venta, dispuestos a ofertar más barato que en el mercado central y en las tiendas ${ }^{16}$.

La nueva ubicación gozó, casi desde el principio, de una gran acogida del público que se ha ido incrementando, en razón, entre otras motivaciones, al aumento demográfico de su área de influencia y a la misma expansión de ésta, acorde con la potenciación de la estructura radial de los servicios de transporte público que en el conjunto urbano de Alicante privilegian la

${ }^{16}$ Según artículos de la prensa alicantina -Información y La Verdad-publicados del 6 al 10 de marzo de 1968. 
convergencia barrios-centro en detrimento de la comunicación entre aquéllos. Y en interacción de causa-efecto, el número de puestos se ha duplicado con creces, merced sobre todo a los de instalación bisemanal que, desbordando las previsiones, ocupan actualmente varias calles adyacentes al paseo -e invadirían otras si el ayuntamiento no lo hubiese vetado taxativamenteal tiempo que constriñen a los puestos de verduras a concentrarse en un flanco junto a la avenida de Alcoy.

El jueves 8 de julio de 1982, día en que se les encuestó, el censo de vendedores se elevaba a 995, de ellos 32 en calidad de «fijos» (una decena con mercancía de uso y el resto con verdulería), 277 puestos de frutas y hortalizas (el 27'8\%), 38 de «varios» (otros comestibles, volatería etc.) y 648 de «general», esto es, mercancía de uso (el 65'1\%). El jueves anterior el monto había ascendido a 1.011 puestos $^{17}$. [107]

De hecho acuden tres clases de vendedores; los clasificados como «fijos» son los que levantan el puesto, que detentan desde antiguo en el mismo sitio del paseo, todos los días hábiles de la semana, satisfaciendo los derechos al municipio por la vía de recibo mensual (de 1.500 a 4.000 ptas. por tenderete de 2 metros de longitud, según el tipo de mercancía), mientras que los demás ambulantes abonan cada día de mercado una cuota de 300 ptas. los de «general», y de 100 ptas. los de fruta y verduras, también por cada $2 \mathrm{~m}$. de puesto. Así lo hacen los que se conviene en llamar «fijos bisemanales», que acuden con regularidad todos los jueves y sábados, usufructuando también un sitio concreto, que se respeta hasta las 9 horas (nótese que los puestos comienzan a levantarse hacia las 6'30 de la mañana), pudiendo después ser ocupado por otro vendedor durante ese día. La tercera clase, sujeta a idénticas cuotas, la constituyen los propiamente «eventuales», que concurren de forma irregular (siempre en jueves o sábado), instalándose en la zona no reservada a medida que van llegando.

Un considerable porcentaje de los vendedores que, de forma regular o no, frecuentan Campoamor los jueves y/o sábados, y en especial entre los no residentes en la capital (bastantes de los avecindados en ella carecen de vehículo), recorren diversos mercadillos de la provincia durante los otros días hábiles.

La procedencia de los vendedores de Campoamor según los resultados de la referida encuesta, sobre un muestreo del $20 \%$, es la siguiente:

TABLA IV

Origen de los comerciantes de Campoamor (8-VII-1982)

\begin{tabular}{|c|c|c|c|c|c|}
\hline Procedencia & $\underline{\text { Ptos. }}$ & $\underline{\%}$ & $\underline{\text { Procedencia }}$ & $\underline{\text { Ptos. }}$. & $\underline{\%}$ \\
\hline 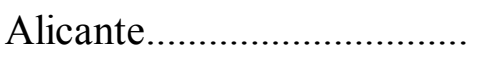 & 93 & 45,81 & Elche...................... & 26 & 12,82 \\
\hline 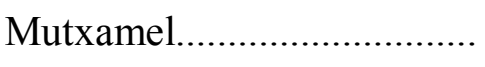 & 4 & 1,97 & Crevillent.............. & 5 & 2,46 \\
\hline S. Vicent, Agost, S. Joan....... & 5 & 2,46 & Santa Pola........... & 1 & 0,48 \\
\hline Camp d'Alacant ................... & $\underline{102}$ & $\underline{50,24}$ & 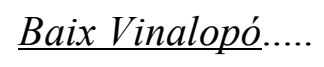 & $\underline{32}$ & $\underline{15,76}$ \\
\hline Сох & 19 & 9,40 & Villena.................... & 5 & 2,46 \\
\hline 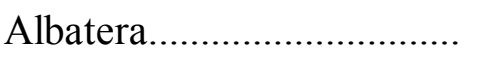 & 13 & 6,40 & Elda...................... & 4 & 1,97 \\
\hline
\end{tabular}

${ }^{17}$ Datos, entre otros, facilitados por el Sr. Sarabia, administrador de este zoco. 


$\begin{array}{lcclcr}\text { Granja de Rocamora........... } & 6 & 6,40 & \text { Castalla.............. } & 2 & 0,98 \\ \text { Orihuela............................ } & 5 & 2,46 & \text { Otros puntos....... } & 4 & 1,97 \\ \text { Callosa de Segura............... } & 3 & 1,48 & \begin{array}{l}\text { Total prov. } \\ \text { Alicante }\end{array} & 197 & 97,05 \\ \text { Rafal y San Fulgencio............ } & 2 & 0,98 & \text { Otras provincias... } & 6 & 2,95 \\ \underline{\text { Bajo Segura ..................................... }} & \underline{48} & \underline{23,67} & \underline{203} & \underline{100}\end{array}$

De ello se desprende que el principal mercado al aire libre de Alicante ejerce una fuerte atracción sobre el comercio ambulante de las comarcas vecinas y aun de puntos relativamente alejados, pues si bien el mayor [108] porcentaje de ambulantes están avecindados en la propia capital (como era de esperar, dado que también es el municipio que cuenta con más licencias o patentes), de hecho el 54'2\% de los vendedores son foráneos llegados desde una dilatada área de influencia, pues más allá de l'Horta d'Alacant (que aporta en torno al 4\%), la comarca más representada es el Bajo Segura, con cerca del $24 \%$ de los vendedores, y en especial tres poblaciones en las que, como se viene señalando, la ambulancia goza de singular arraigo: Cox, Albatera y, en menor grado, Granja de Rocamora, a las que corresponde el 18'7\% de los puestos encuestados. A continuación figura el Baix Vinalopó, con el 15'7\%, en su mayoría procedentes de Elche, otro de los grandes focos de este comercio. A excepción del resto del Valle del Vinalopó que, bien comunicado con la capital, suma el 5'4\%, las demás áreas provinciales apenas cuentan. Por último, en torno al 3\% procede de Murcia y de otras provincias (Albacete, Ciudad Real, Cuenca y Granada, en ese día de referencia).

Dado que goza de una vasta clientela potencial, Campoamor comercializa una variopinta y abigarrada gama de productos, se puede decir que todos los autorizados, en mayor o menor grado (lo que depende también de la época del año; hay, p.ej., más juguetes por Navidad y artículos de playa en verano).

La relación de mercancías con el origen de los comerciantes que las ofertan, según la mencionada encuesta sobre un quinto de los puestos, presenta las siguientes características:

TABLA V

Campoamor. Clases de mercancía y procedencia del vendedor (8-VII-1982)

\begin{tabular}{|c|c|c|c|}
\hline $\begin{array}{l}\text { Frutas } \\
\text { verduras }\end{array}$ & $\underline{\text { Calzado }}$ & $\begin{array}{l}\text { Tejidos y } \\
\text { confección }\end{array}$ & $\begin{array}{l}\text { Artículos } \\
\text { de hogar }\end{array}$ \\
\hline 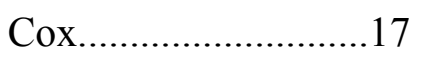 & Alicante........28 & Alicante............24 & Alicante............7 \\
\hline Granja Rocamora........5 & Elche.............12 & Albatera...........12 & Villena..............2 \\
\hline Otros B. Segura...........4 & Elda...............4 & $\begin{array}{l}\text { Otros B. } \\
\text { Segura ............... }\end{array}$ & Santa Pola........1 \\
\hline Alicante............................ & Albatera.........1 & Elche................10 & Murcia..............1 \\
\hline $\begin{array}{l}\text { Otros Camp } \\
\text { d'Alacant...................6. }\end{array}$ & Benidorm.......1 & Crevillent..........3 & \\
\hline
\end{tabular}


Elche, Villena y Aspe. .5

Total 49

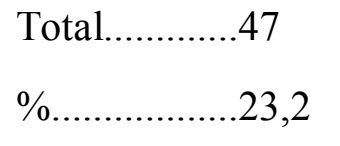

$\%$ de

encuestados.......24,1
Orihuela........1 Otros puntos.....7

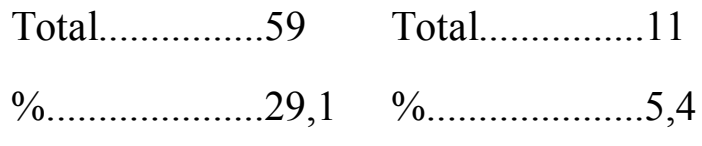

Otras mercancías: 37 puestos (18’2\%), de ellos 22 de Alicante. [109]

La tabla ratifica lo antes afirmado sobre la existencia de ciertas especializaciones por núcleos. Entre las excepciones destaca el caso de Alicante, ciudad fuertemente terciarizada, que ofrece múltiples servicios al ambulante (redes de distribución, almacenes, etc.) y una gran clientela potencial in situ, autóctona y flotante (turismo), de ahí que cuenta con vendedores de cualquier tipo de mercancía, sobre todo en las de uso (calzado, confección y varios). En frutas y hortalizas, sin embargo, son mayoritarios los llegados de Cox y Granja, como es usual en muchos zocos de las comarcas meridionales. Después de los alicantinos, el calzado lo comercian desde los centros manufactureros del Vinalopó, sobre todo los ambulantes ilicitanos quienes asimismo ocupan un tercer lugar en el capítulo de la confección, después de los albaterenses, que son especialistas en estos géneros.

Sin duda, los mercadillos suponen una competencia para ciertos almacenes y tiendas, pero también es cierto que en la zona donde aquéllos se establecen generan un efecto de inducción sobre el comercio sedentario, en mayor o menor grado. Así, en la calle Calderón, mientras fue sede de los ambulantes de mercancías de uso, se instalaron numerosas tiendas, que todavía le prestan hoy un ambiente comercial muy superior al de las vías adyacentes; y en el primer tramo de la avenida de Alcoy, limítrofe con Campoamor, se está repitiendo en cierto modo el fenómeno: allí se ubican cerca de la veintena de comercios fijos.

A modo de apéndice de Campoamor, el centro de Alicante cuenta todavía con el mercadillo de frutas y hortalizas de la calle de Velázquez que, aunque situado junto al mercado central, se vincula más a aquel zoco por ser un precedente del mismo (existe desde los años veinte) y por presentar caracteres similares (venta en tenderetes que se montan al aire libre). Pero también hay una serie de rasgos que lo diferencian de Campoamor; la de Velázquez es una calle muy céntrica, con tráfico rodado fuera de los días de mercado (jueves y sábados); orientado éste en exclusiva a la venta de productos agrícolas, cuenta hoy con 143 puestos fijos (cuyos beneficiarios abonan 700 pesetas mensuales al municipio) ${ }^{18}$.

Desde sus orígenes acogió a colliters o cosechadores natos, agricultores que acudían allí a vender el producto de su trabajo en las huertas de Mutxamel, Sant Joan, Xixona, Cox, etc. En la actualidad todavía venden con cartilla agrícola (en Campoamor se exige licencia fiscal). A la pregunta ilos productos que vende son de cosecha propia?, los comerciantes de fruta y verduras contestaron: [110]

\section{En la calle de Velázquez}

Sí.......................... 20 (64'5\%)

\section{En el paseo de Campoamor}

Sí..............................15 (48’4\%)

\footnotetext{
${ }^{18}$ Informes del Sr. Benito, administrador del mercado central y del zoco de Velázquez.
} 
No .0

Sólo en parte......9 (29’0\%)

Sin respuesta......2 (6'5\%)

Total muestra.....31 (100\%)
No

$9\left(29^{\prime} 0 \%\right)$

Sólo en parte $5(16 ' 1 \%)$

Sin respuesta $2(6,5 \%)$

Total muestra $31(100 \%)$

Con todo, en opinión de otras fuentes los entrevistados tienden a responder afirmativamente por considerar que para el cliente la mercancía del cosechero va aureolada de una imagen de garantía y buen precio. Se afirma que «hoy todos los vendedores compran en almacén» en mayor o menor cuantía, incluso los de Velázquez, en donde la figura del colliter nato va desapareciendo en favor del revenedor.

La procedencia de los comerciantes de la calle de Velázquez, según encuesta por muestreo en 8 de julio de 1982, continúa siendo la tradicional: el 48\%4\% son de Cox (mayoritarios también en Campoamor en el ramo de la alimentación) y otro 9'7\% proceden también del Bajo Segura (Granja, Callosa, Formentera...); el 22'6\% son de l'Horta d'Alacant, en especial de Mutxamel, municipio éste de gran tradición en vendedores-cosecheros (de este origen hay varios ambulantes en Campoamor y una quincena de minoristas en el mercado central); en menor proporción acuden desde Xixona (9\%), Villena (6\%), Elche, etc.

Cabe observar, por último, que Alicante cuenta con otros dos mercadillos al estilo de Campoamor, pero de menor importancia, situados en sendos barrios y alrededor de otros tantos mercados de abastos, los de Benalúa y Carolinas; entre ambos suman unos 400 puestos de venta. Una razón de peso justifica su existencia, como también la de Campoamor-Velázquez, por lo que respecta a la oferta alimentaria, y estriba en que la infraestructura en mercados municipales de abastos con que cuenta la ciudad resulta claramente insuficiente -en número, en su reparto espacial y en dotación de puestos de venta- para atender a la cuantiosa demanda, sobre todo la de los barrios periféricos; la política del ayuntamiento se encamina a mejorar las condiciones de los mercados existentes, y a descentralizar la oferta, erigiendo otros en los barrios (como el de Babel, inaugurado en octubre del presente año).

Los mercadillos del Bajo Segura.- Se han seleccionado, como quedó expuesto, los ubicados en cuatro poblaciones de distintos tamaños y funciones: Torrevieja, litoral, turística, que censó 12.314 habitantes en 1981; Orihuela, capital comarcal, con 24.667 habs.; Almoradí, ciudad agrícola de 13.398 habs., y el pequeño núcleo rural de Rojales, con 4.117 habs. A partir de las encuestas realizadas en el verano de 1981 [111]

\section{Campoamor}




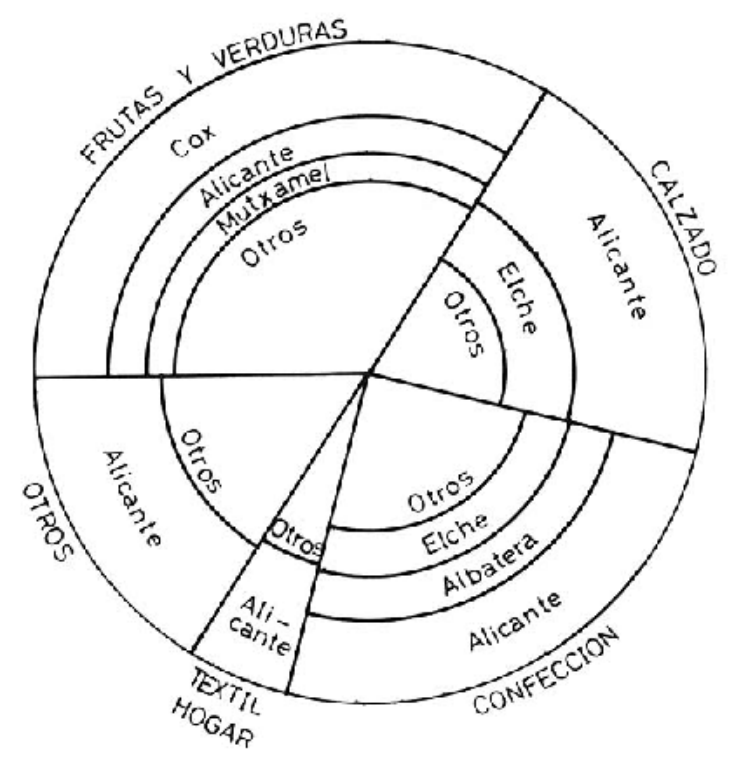

Mercadillos de Campoamor (Alicante) y de Torrevieja: principales procedencias de los vendedores según el tipo de mercancía que comercializan.

\section{Torrevieja}

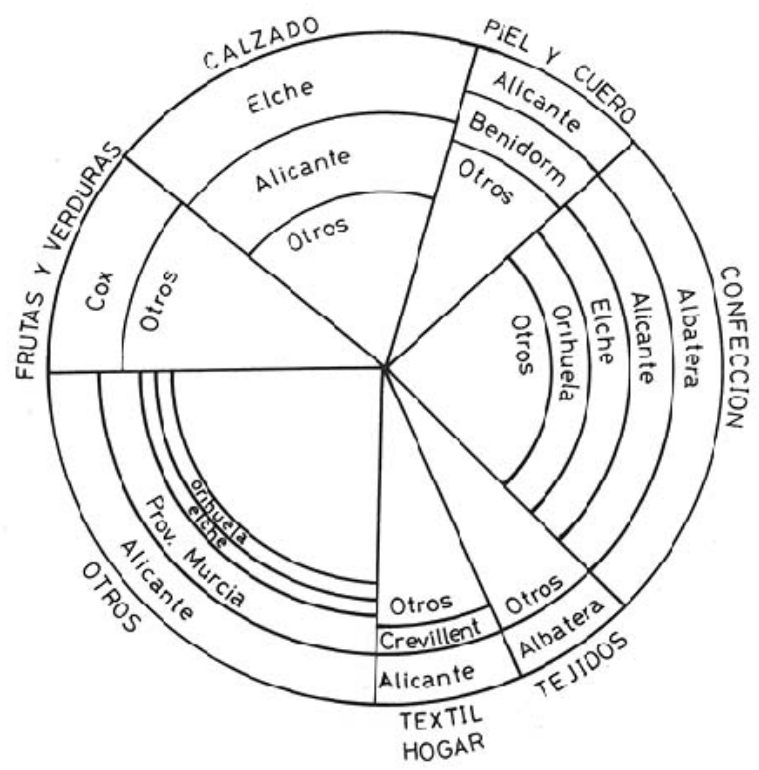




\section{Orihuela}

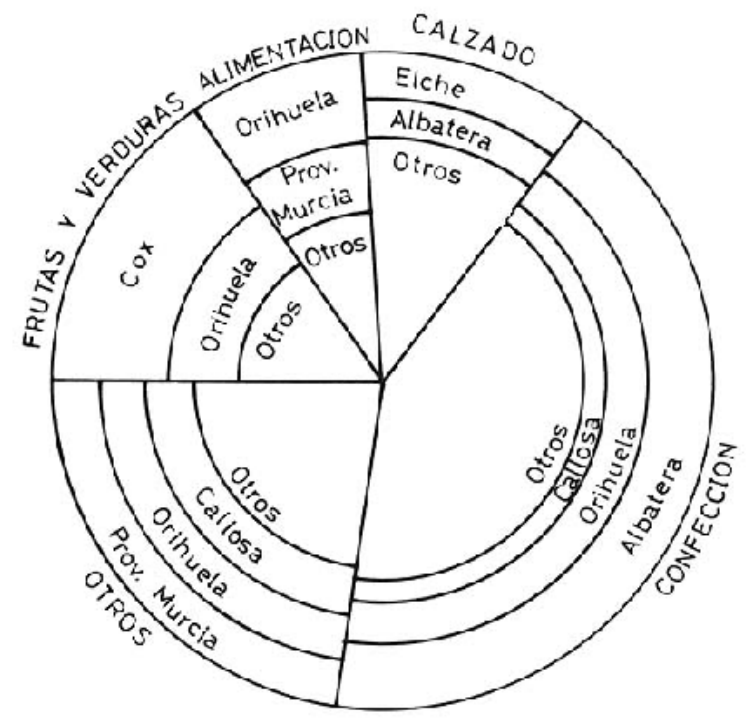

Mercadillos de Orihuela y de Almoradí: principales procedencias de los vendedores según el tipo de mercancía que comercializan.

\section{Almoradí}

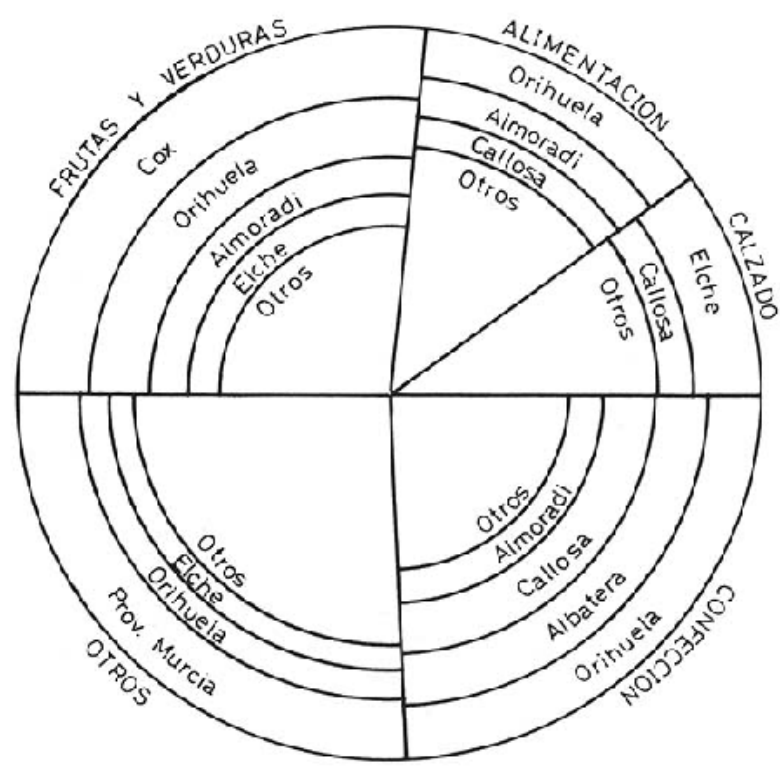

[113]

se elaboran las tablas expuestas a continuación (fueron entrevistados todos los comerciantes de los cuatro zocos). 
TABLA VI

Origen geográfico de los vendedores

\begin{tabular}{|c|c|c|c|c|c|c|c|c|}
\hline \multirow[b]{2}{*}{ Procedencia } & \multicolumn{2}{|c|}{ TORREVIEJA } & \multicolumn{2}{|c|}{ ORIHUELA } & \multicolumn{2}{|c|}{ ALMORADI } & \multicolumn{2}{|c|}{ ROJALES } \\
\hline & Ptos. & $\%$ & Ptos. & $\%$ & Ptos. & $\%$ & Ptos. & $\%$ \\
\hline Albatera & 60 & 10,26 & 57 & 17,81 & 15 & 7,25 & 4 & 6.15 \\
\hline Callosa de Segura & 19 & 3,25 & 32 & 10,00 & 21 & 10.14 & 5 & 7,69 \\
\hline Cox & 30 & 5,13 & 36 & 11,25 & 21 & 10,14 & 8 & 12,31 \\
\hline Granja Rocamora & 11 & 1,88 & 3 & 0,94 & 2 & 0,97 & 1 & 1,54 \\
\hline $\begin{array}{l}\text { Orihuela } \\
\text { On }\end{array}$ & 42 & 7,18 & 80 & 25,00 & 37 & 17,87 & 16 & 24,62 \\
\hline Otros Bajo Segura & 41 & 7,01 & 28 & 8,75 & 48 & 23.19 & 12 & 18,46 \\
\hline Crevillent & 14 & 2,39 & 13 & 4,06 & 6 & 2,90 & 2 & 3,08 \\
\hline Elche & 94 & 16,07 & 23 & 7,19 & 21 & 10,14 & 9 & 13,85 \\
\hline Santa Pola & 15 & 2,56 & & & & & & \\
\hline Alicante & 132 & 22,56 & 5 & 1,56 & 5 & 2,42 & & \\
\hline Otros Camp d'Alacant & 3 & 0,51 & 1 & 0,31 & & & & \\
\hline Vinalopo Mitjà & 20 & 3,43 & 1 & 0,31 & 1 & 0,48 & 1 & 1,54 \\
\hline La Marina & 27 & 4,61 & & & & & & \\
\hline Otras comarcas & 6 & 1,03 & 2 & 0,63 & 2 & 0,97 & 1 & 1,54 \\
\hline Prov. de Murcia & 55 & 9,40 & 38 & 11,88 & 26 & 12,56 & 3 & 4.61 \\
\hline Otras provincias & 16 & 2,73 & 1 & 0,31 & 2 & 0,97 & 3 & 4,61 \\
\hline TOTAL & 585 & 100 & 320 & 100 & 207 & 100 & 65 & 100 \\
\hline
\end{tabular}

Pese a su menor rango demográfico respecto a la cabecera comarcal, durante el verano Torrevieja es un mercado muy atractivo para el ambulante por ser frecuentado por la numerosa población flotante, motivada por los precios cuando no por la remembranza del exótico zoco y el respirar un ambiente «típico». De ahí su mayor número de puestos, 585, y la captación de vendedores en una amplia zona geográfica, pues sólo un 34’7\% de los mismos provienen de la propia comarca, frente a una nutrida representación tanto de Alicante capital (22\%5\%) como del Baix Vinalopó (21\%), y no faltan los llegados de áreas muy lejanas (Vinalopó Mitjà, La Marina, etc.), incluyendo un 12 ' $1 \%$ de ambulantes extraprovinciales, sobre todo murcianos.

En Orihuela, sin embargo, cerca de tres cuartas partes de los 320 puestos del mercadillo corresponden a vendedores de su comarca; es más, el 25\% son residentes en ese municipio (ciudad y pedanías), el cual, según se vio en la tabla II, ostenta el cuarto lugar provincial en licencias de ambulancia. El área de atracción, consiguientemente, es más reducida que la torrevejense, pues más allá de las aportaciones de la vecina Huerta de Murcia y del Baix Vinalopó (con un 11\% en ambos casos), apenas drena vendedores (el 3\% de los puestos). [114]

Estas características se mantienen grosso modo en los otros dos mercados, de menor clientela potencial, pues en Almoradí, con 207 puestos, el 70\% los detentan ambulantes de la comarca y un porcentaje similar registra Rojales, con 65 puestos.

El contraste entre los mercadillos estudiados es quizá más patente si atendemos al tipo de mercancías ofertadas. 
TABLA VII

Clases de mercancias, por puestos

\begin{tabular}{|c|c|c|c|c|c|c|c|c|}
\hline Mercancias & Ptos. & $\%$ & Ptos. & $\%$ & Ptos. & $\%$ & Pros. & $\%$ \\
\hline Frutas y verduras & 64 & 10,94 & 49 & 15,31 & 55 & 26,58 & 21 & 32,31 \\
\hline Prod. alimenticios & 31 & 5,30 & 27 & 8,44 & 28 & 13,53 & 11 & 16,92 \\
\hline Confección & 142 & 24,28 & 135 & 42,19 & 50 & 24,16 & 15 & 23,08 \\
\hline Tejidos & 34 & 5,81 & 13 & 4,06 & 9 & 4,36 & 4 & 6,15 \\
\hline Textil hogar & 41 & 7,00 & 2 & 0,62 & 1 & 0,48 & - & - \\
\hline Mercería & 10 & 1,71 & 10 & 3,12 & - & - & 1 & 1,54 \\
\hline Calzado & 108 & 18,46 & 36 & 11,25 & 21 & 10,14 & 1 & 1,54 \\
\hline Artic. piel, cuero & 49 & 8,38 & 5 & 1,56 & 4 & 1,93 & 1 & 1,54 \\
\hline Bisuteria & 13 & 2,22 & 8 & 2,50 & 5 & 2,41 & 3 & 4,61 \\
\hline Loza y cerámica & 12 & 2,05 & 12 & 3,75 & 7 & 3,38 & 1 & 1,54 \\
\hline Plantas y flores & 9 & 1,54 & 6 & 1,88 & 5 & 2,41 & 4 & 6,15 \\
\hline Artic. de limpieza & 7 & 1,20 & 3 & 0,94 & 5 & 2,41 & 1 & 1,54 \\
\hline Varios & $65^{111}$ & 11,11 & 14121 & 4,38 & $17^{13}$ & 8.21 & 2 & 3,08 \\
\hline TOTAL & 585 & 100 & 320 & 100 & 207 & 100 & 65 & 100 \\
\hline
\end{tabular}

(1) Regalos, 12; juguetes, 10; mimbre y madera, 8; discos, 7; ferreteria, 6; antigüedades, 2; monedas, 1

(2) Regalos, 5: discos, 3 ; lanas, 2 .

(3) Regalos, 6; discos, 3; juguetes, 3; mimbre y madera, 2.

En efecto, en los zocos mayores la gama de productos comercializados es más amplia y, sobre todo, se evidencia en ellos una superior proporción de géneros de uso, más alta cuanto menor sea su cotidianidad. Así, el porcentaje de puestos de alimentación evolucionó claramente en razón inversa a la categoría del zoco (del 32\% en Rojales a sólo un $10 \%$ en Torrevieja), en beneficio de las mercancías más singulares o menos cotidianas, como es el caso del calzado, que presenta la mayor proporción de puestos de venta en Torrevieja $\left(18^{\prime} 4 \%\right.$, frente a un único puesto en Rojales), donde también está bien representada, con diferencia notable sobre los otros mercados, la confección en piel, cuero y materiales sucedáneos $\left(8^{\prime} 4 \%\right.$, frente a menos del $2 \%$ los restantes), así como los textiles para el hogar (7\%, contra menos del 1\%); el capítulo de «varios» también es más nutrido en Torrevieja, contando con diversos artículos no ofertados en los otros zocos como los de relojería, antigüedades [115] y ferretería. En confección, sin embargo, la situación es pareja, salvo en Orihuela donde se destaca con el $42 \%$ de los puestos.

En los tres mercados principales invariablemente el grueso de la oferta se basa en la trilogía productos hortofrutícolas, confección textil y calzado (del 53\% al 68\% de los puestos). [116] 


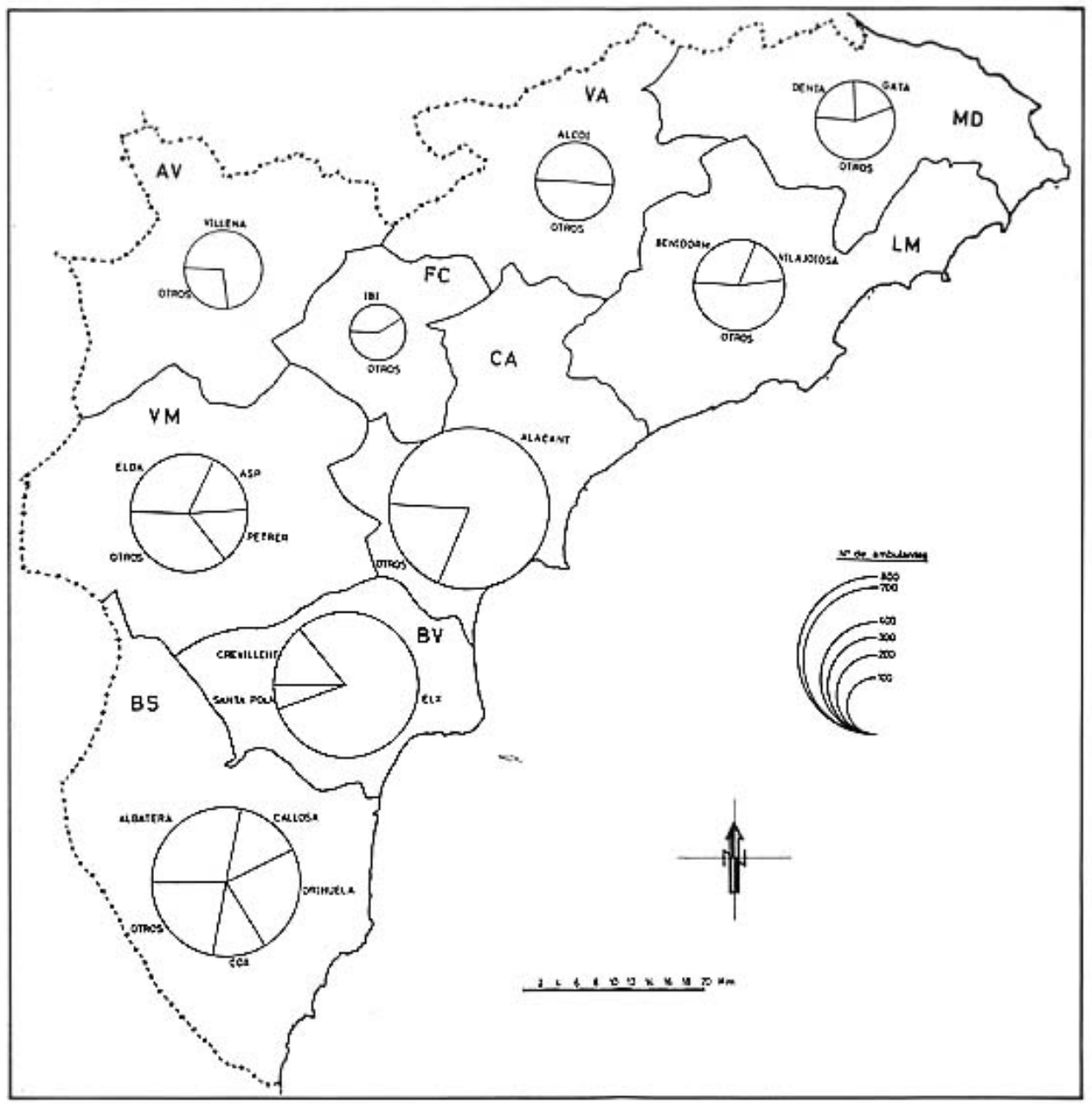

Mapa 1.- Reparto comarcal de los ambulantes, según su residencia habitual. 


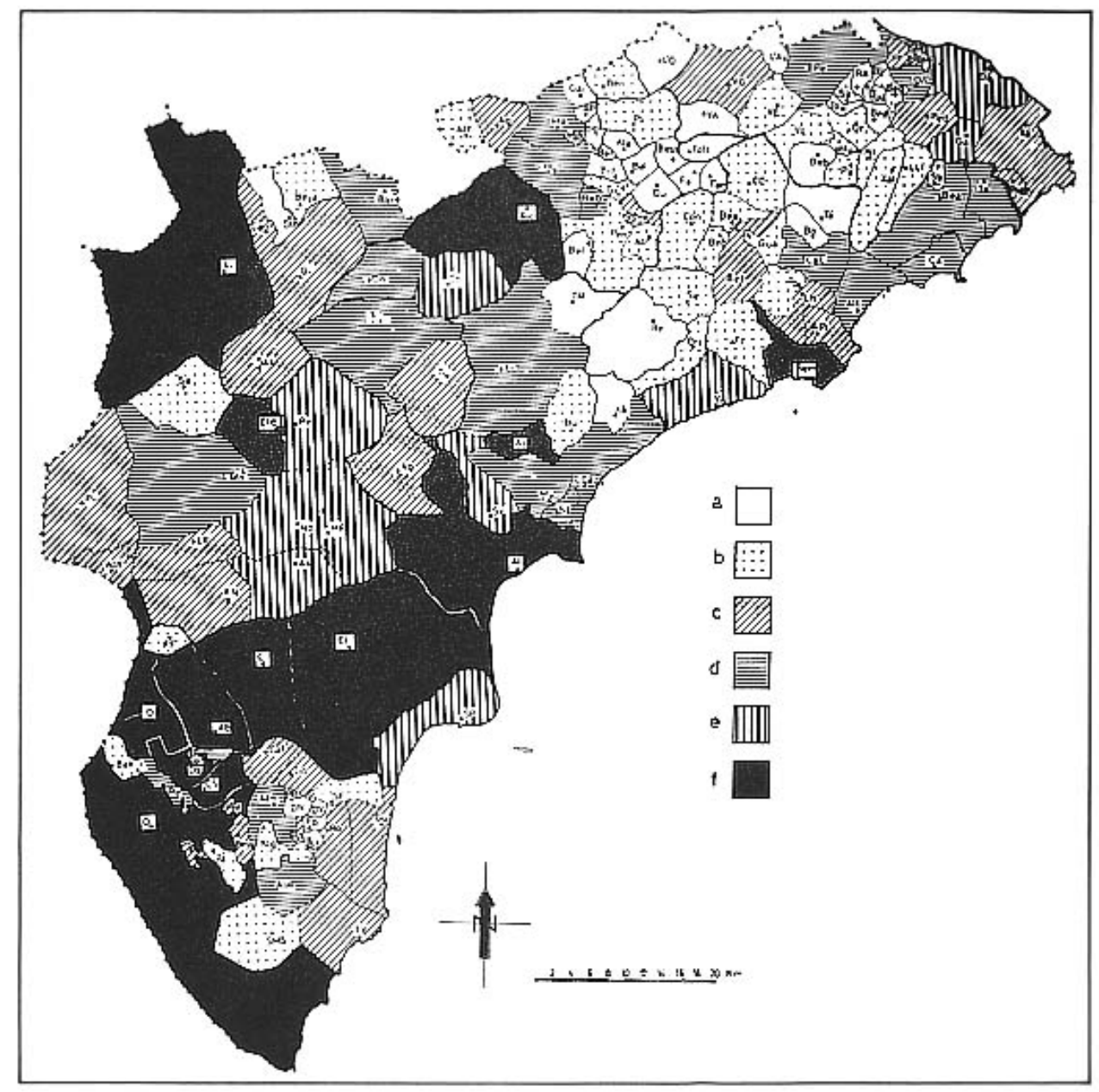

Mapa 2.- Distribución de los ambulantes por municipios de residencia.

a) Ningún vendedor; b) de 1 a 5 vendedores; c) entre 6 y 15; d) de 16 a 30; e) entre 31 y 80; f) más de 80 . 


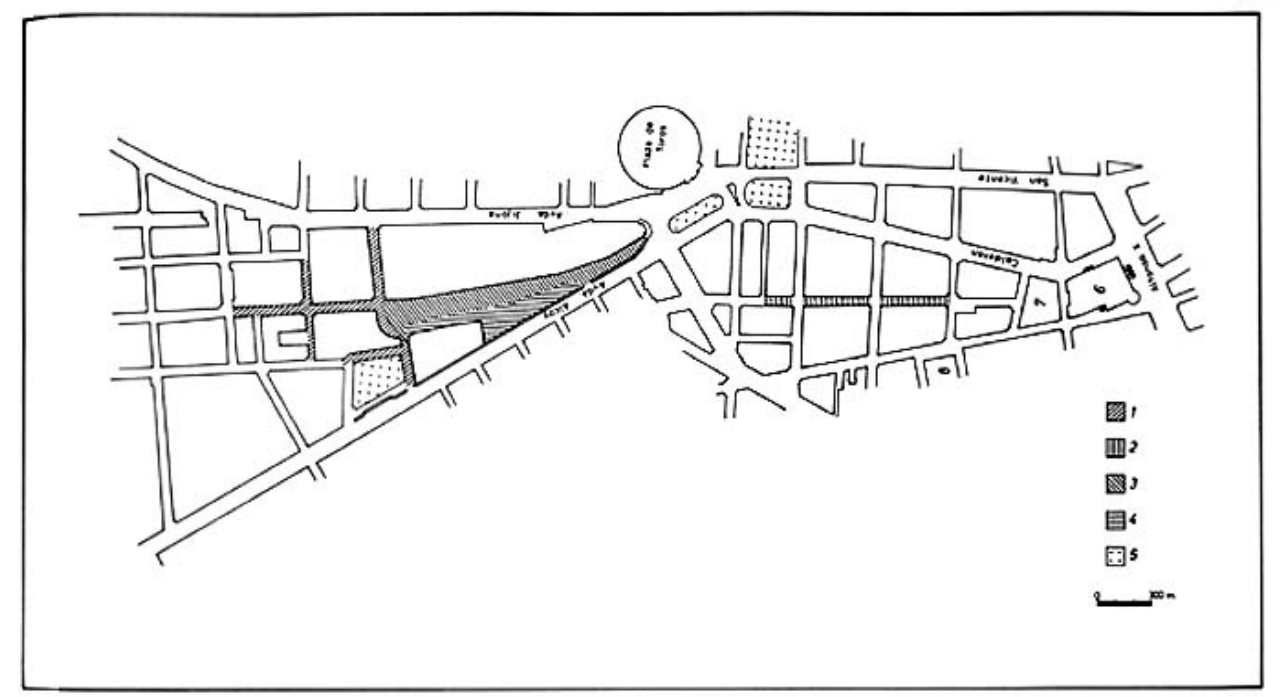

Plano de localización del mercadillo de Campoamor y su anexo de Velázquez (ciudad de Alicante)

1) Puestos de mercancías de uso en el paseo de Campoamor;

2) puestos de frutas y verduras;

3) calles habilitadas como ampliación del zoco para mercancías varias;

4) calle de Velázquez (zoco de vendedores-cosechadores);

5) zonas ajardinadas en los accesos al paseo;

6) edificio del mercado central de abastos;

7) nave de ampliación del mismo (para frutas y hortalizas), y

8) antigua lonja de verduras de San Fernando. 